\title{
A Model Based Examination of AIDS: Its Causes and Probable Course ${ }^{1}$
}

by

James R. Thompson

Technical Report 86-25

${ }^{1}$ This work was supported in part by the United States Army Research Office (Durham) under DAAG 29-85-K-0212 at Rice University. 

A MODEL BASED EXAMINATION OF AIDS: ITS CAUSES AND

PRIRARIE IDIIRSE*

James R. Thompson, Rice University and M.D. Anderson Hospital

A customary approach to the rontrol of contaginus diseases in contemporary America is via medical intervention, either by preventive vaccination or by the use of antibiotics. Historically, sociological control of epidemics has been the more customary method. This has been due, in part, to the fact that vaccines were unknown before the Nineteenth Century and antibiotics hefore the Twentieth century.

In the case of some ancient peoples, a large portion of the system of laws dealt with the means of sociological control of epidemics. For example, it should be noted that the 13th, 14th and half of the 15th chapter of Leviticus (131 verses) are dedicated for the sociological control of leprosy. We might contrast this with the fact that the often mentioned dietary (kasher) laws receive only one chapter, the 11 th, with a total of 47 verses.

The notion that epidemics can always be controlled by a shot or a pill rather than by the generally more painful sociological methods caused much human suffering even before AlDS. For example, First World medicine has largely displaced isolation as a control for leprosy in the Third World. Because the methods have been less effective in practice than hoped, we have the spectacle in some countries of three generations of a family sharing the same roof and the disease of leprosy. Only in the

*This work was supported in part by the Army Research Office (Durham) under DAAG-29-85-K-0212 at Rice University. 
$1980^{\circ}$ 's have we (apparently) reached the level of medical control necessary to protect individuals against the effects of leprosy. But, in some sense, we have acted for some decades as though we were in possession of an anti-leprosy technology which we did not, in actuality, have.

In the case of AlDS, we see an even more difficult (of medical control) disease than leprosy. At present, the amount of federal funds expended on AIDS is over $20 \%$ of the total federal funding for research on all oncological diseases (of which AIDS is considered to be one). My own discussion with colleagues involved in the investigation indicates that a vaccine or a cure is extremely unlikely in the the-r future. Accordingly, we are confronted with a disease with a $100 \%$ fatality record and a per patient medical cost (using the present heroic intervention) in the $\$ 100,000 /$ case range. We must ask the question of whether the present main thrust of attack can be deemed optimal or even intelligent.

Let us consider an argument, developed in 1983 [1], when the disease was first beginning to produce deaths in the several hundreds First of all, we can determine the probability that a random infective will transmit the disease to a susceptible during a time interval $[t, t+\Delta t]$.

(1) Prob [transmission in $(t, t+\Delta)]=k \Delta t \times x /(X+Y)$

whore

$k=$ number of contacts per unit time

$\alpha=$ probability of contact causing AIDS

$X=$ number of susceptibles

$Y=$ number of infectives. 
To get the expected total increase in the infective population during $t, t+\Lambda t l$, ye multin!y the aboye by $Y$, the number of infectives.

(2) $\Delta E(Y)=$ YPr(transmission in $[t, t+\Delta t])$.

For larģe nopulations, we can assume, under fairly general conditions, that the expected total change in $Y$ is a very nearly equal to a deterministic $Y$, i.e.,

(3) $\Delta \mathrm{E}(\mathbf{Y}) \approx \Delta \mathbf{Y}$.

Letting $\Delta$ t go to zero, this yields, immediately

(4) $d Y / d t=k \propto X Y /(X+Y)$

$d X / d t=-k \circ X Y /(X+Y)$.

Now, we must allow for immigration into the susceptible population $(\lambda)$, and emigration $(\mu)$ from both the susceptible and infective populations ond for morginal increose in the emigration from the infective population due to AIDS (b), from sickness and death. Thus we have the improved differential equation model

(5) $\mathrm{dY} / \mathrm{dt}=\mathrm{k} \propto \mathrm{XXY} /(\mathrm{X}+Y)-(\delta+\mu) Y$

$\mathrm{dX} / \mathrm{dt}=-\mathrm{k \alpha XX} /(\mathrm{X}+\mathrm{Y})+\lambda-\mu \mathrm{X}$

where $\ddot{b}=A 1 \bar{D}$ s death rate,

$\lambda=$ immigration rate,

$\mu=$ emigration rate.

For early stages of the disease, $X /(X+Y) \approx 1$. Accordingly, we may write the approximation:

(6) $\mathrm{dY} / \mathrm{dt} \approx[\mathrm{k} \alpha-\mu-\delta] Y$.

This gives us the solution:

(7) $y=Y(0) \exp \{[k \alpha-\mu-\delta] t\}$ 
Now, we shall use some rough guesses for some of the parameters in the equations ahove. We shall assume that, absent AIDS, the total target population is $3,000,000$. We shall assume that an individual stays in this population an average of 15 years (yielding $\mu=1 /(15 \times 12)=.00556$ ). We will use as the average time an infective remains sexually active 10 months byalding $6=1$ ). To maintain the population of $3,000,000$ (absent A!DS), then, we require

(8) $\mathrm{dX} / \mathrm{dt}=\lambda-\mu \mathrm{X}=0$

or $\lambda=16,666$. Now, if we combine these figures with early death dota from AIDS, we can use the approximation for $y$ to obtain an estimate for $k \times \approx 263$. Below, we show a table of predicted and observed [2] AIDS figures using the estimated parameters.

\section{Toble 1. AIDS CASES}

Date

May 82

Aug 82

Hov 82

Feb. 83

May 83
Actual

255

475

750

1,150

1,675
Predicted

189

339

580

967

1,587

Now, using the somewhat smaller kx value of .25 and an intial infective population of 2,000 , we come up with the following

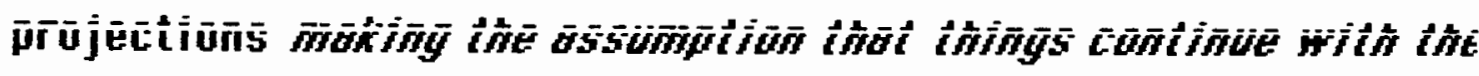

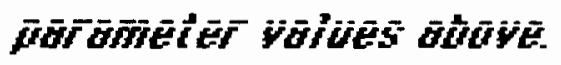


Tab!e 2. PROJECT!ONS OF A!DS $\mathrm{W} ! T H \mathrm{kA}=.25$

YEAR

CUM. DEATHS

2
10
15
20

$\begin{array}{rr}6,434 & .004 \\ 42,210 & .021 \\ 226,261 & .107 \\ 903,429 & .395 \\ 2,003,633 & .738 \\ 3,741,841 & .578 \\ 4,650,124 & .578 \\ 5,562,438 & .578\end{array}$

FRACTION INFECTIVE

004

021

107

395

738

578

578

578

The fraction infective column has been given, since, in the absence of state intervention or medical breakthrough, it is this yariable which proyides the (sociological) feedback for the control of the disease. Any visibility of a loathsome and fatal disease in the proportion range of one percent of the target population will almost certain!y cause members of that population to consider modifying their membership in it. In the days of plague in Western Europe, one could attempt to leaye centers of congested population. It rould appear likely that AIDS will cause a diminution of $\lambda$ and $k$ and an increase of $\mu$. We note that the period for doubling the number of AIDS cases in the United States in 1982 was essentially 5 months in 1982, but has increased to nearly a year at present. [3].

Let us consider, for example, the effect of diminishing $k$. We note that in the early stages of the disease, an aquilibrium value of $k x=.1056$ is obtained. At this value, with all other 
parameters held constant, the total body count after 20 years is 47, B48 with a fraction of infectives quickly reaching 000668 . Now, let us suppose that fear reduces $k$ to $20 \%$ of its present value, by the use of condoms and some restraint in activity. Then, the tahle below shows that the disease quickly retreats into epidemiological insignificance.

Table 3. PROJECTIONS OF AIDS WITH ko $=.05$

$\begin{array}{ccc}\text { YEAR } & \text { CUM DEATHS } & \text { FRACTIO } \\ 1 & 1,751 & .00034 \\ 2 & 2,650 & .00018 \\ 3 & 3,112 & .00009 \\ 4 & 3,349 & .00005 \\ 5 & 3,471 & .00002 \\ 10 & 3,594 & .000001\end{array}$

But, let us suppose that a promiscuous fraction, $p$, retains a ko yalue $L$ times that of the less promiscuous population. Our model becomes:

(9) $d Y_{1} / d t=k \propto X_{1}\left(Y_{1}+L Y_{2}\right) /\left(X_{1}+Y_{1}+L\left(Y_{2}+X_{2}\right\}\right)-(\delta+\mu) Y_{1}$

$$
\begin{aligned}
& d Y_{2} / d t=\operatorname{koL} L X_{2}\left(Y_{1}+L Y_{2}\right) /\left(X_{1}+Y_{1}+L\left(Y_{2}+X_{2}\right\}\right)-(b+\mu) Y_{2} \\
& d x_{1} / d t=-\operatorname{kox} x_{1}\left(Y_{1}+L Y_{2}\right) /\left(X_{1}+Y_{1}+L\left(Y_{2}+X_{2}\right\}\right)+(1-p) \lambda-\mu x_{1} \\
& d x_{2} / d t=-k \propto L X_{2}\left(Y_{1}+L Y_{2}\right) /\left(X_{1}+Y_{1}+L\left(Y_{2}+X_{2}\right\}\right)+p \lambda-\mu X_{2}
\end{aligned}
$$

Below, we consider the case where $k \alpha=.05$,

$\mathrm{L}=\mathrm{J}_{\boldsymbol{s}}$ and $\mathrm{g}=. \mathrm{I}$. 
Tahle 4. PROJECTIONS OF AIDS WITH $\mathrm{n}=.10$

$\begin{array}{rcc}\text { YEAR } & \text { CUM. DEATHS } & \text { FRACTION INFECTIVE } \\ 1 & 2,100 & .0005 \\ 2 & 4,102 & .0006 \\ 3 & 6,367 & .0007 \\ 4 & 9,054 & .0008 \\ 5 & 12,274 & .0010 \\ 10 & 40,669 & .0020 \\ 15 & 105,076 & .0059 \\ 20 & 228,065 & .0091\end{array}$

We notice how the presence of even a small promiscuous population can stop the demise of the epidemic. But, if this proportion becomes sufficiently small, then the disease is removed from an epidemic to an endemic situation, as we see below with $\mathrm{p}=.05$ and all other parameters the same as above.

Tahle 5. PROJECTIONS OF AIDS WITH p $=.05$

YEAR

\section{1}

2

3

4

5

10

15

20
CUM. DEATHS FRACTION INFECTIVE

$1,9 ! 7$

3,272

4,344

5,228

5,971

Q, 263

9,247

9,672
.00043

.00033

.00027

.00022

.00019

.00008

.00003

.00002 
The dramatic effert of a small promiscuous population may be considered in the case where $90 \%$ of the population has a $k 0$ of 02 and $10 \%$ has a ko of .32 . This gives a population with an guerall ko of .05. If this low value is mointained across the population, then we have seen that the disease quickly dies out. But consider the situation when the mix is given as above.

Table 6. PROJECTIONS OF AIDS WITH $p=.1, k \alpha=.02, L=16$

$\begin{array}{ccc}\text { YEAR } & \text { CUM. DEATHS } & \text { FRACTION INFECTIVE } \\ 1 & 2,184 & .0007 \\ 2 & 6,536 & .0020 \\ 3 & 20,583 & .0067 \\ 4 & 64,157 & .0197 \\ 5 & 170,030 & .0421 \\ 10 & 855,839 & .0229 \\ 15 & 1,056,571 & .0122 \\ 20 & 1,269,362 & .0182\end{array}$

One prodiction obout AlDS is that there is a "Typhoid Mary" phenomenon. That means that the actual transmission rate is much higher than had been supposed, but only a fraction of the infected develop the disease quickly. Another fraction become carriers of the disease without themselves actually developing the physical menifestations of the diseese, except possibly aftar a long intaryal of time. To sae the effects of such a fhenofinefion, let us suppose ku $=.05$, but $50 \%$ of those who contract the disease have a life expectancy of 100 months instead of only 10 . 
Table 7. PROJECTIONS OF AIDS WITH kox=.05 AND HALF OF THE INFECTIVES $W$ ITH $d=.01$

$\begin{array}{ccc}\text { YEAR } & \text { CUM. DEATHS } & \text { FRACTION INFECTIVE } \\ 1 & 1,064 & .00066 \\ 2 & 1,419 & .00075 \\ 3 & 2,801 & .00089 \\ 4 & 3,815 & .00110 \\ 5 & 5,023 & .00130 \\ 10 & 16,032 & .00330 \\ 15 & 44,340 & .00860 \\ 20 & 115,979 & .02210\end{array}$

Such a disestrous scenorio is, naturally, made much worse as we increase the fraction of those with the long sexually active life expectancy. For example, if this proportion is $90 \%$, we have

Table 8. PROJECTIONS OF AIDS WITH 90\% HAVING LIFE EXPECTANCY OF 100 MONTHS

$\begin{array}{ccc}\text { YEAR } & \text { CUM. DEATHS } & \text { FRACTION INFECTIVE } \\ 1 & 457 & .0094 \\ 2 & 1,020 & .0013 \\ 3 & 1,808 & .0020 \\ 4 & 2,943 & .0028 \\ 5 & 4,587 & .0041 \\ 10 & 32,911 & .0260 \\ 15 & 194,154 & .1441 \\ 20 & 776,146 & .4754\end{array}$


If the Typhoid Mary phenomenon is an actuality, then the effect of AlDS is likely to be catastrophic indeed. (Note that no presence of a promiscous subpopulation is necessary to cause this catastrophic scenario.) However, this would imply that A!DS was a new disease, contrary to the historical evidence. It seems most likely that AIDS has always been endemic in a species of Central African monkey and that its presence in the human population is of long standing. Indeed, the present entry into the United States appears to be via Haiti, which has not had significant African immigration for centuries. Since the disease has heen noted in the Inited states, studies show the disease present in Tanzania, Uganda, Zaire, etc. These studies contain even more noise than those in the United States, which are very noisy indeed. (Also, it is interesting to note that claims have been made that the disease is frequently now of epidemic proportions in the heterosexual population. How much nf this latter phenomenon is real, and how much of the real heterosexual cases is due to nonsexual modes, e.g., zealous local medicos dispensing shots with unsterilized needles, is a matter of conjecture. We need quickly to find out what is going on in with AlDS in Africa. If there is truly a high heterosexual transmission rate there, we must find out why that does not to be the case in the United States.) How likely, we must ask, is it that genetic drift in the AIDS virus would have proceeded in such widely separated populations to produce epidemics in both the lnited states and Centra! Africa at the same time? Anerdntal!y, a nathn!nngist at the Texas Medical Center has informed me that some of his colleagues, nearing retirement, now recall young male patients with AIDS symptoms as long as 30 years ago, but in such occasional numbers that there was no 
attempt to characterize such rare occurrences in any systematic fashion.

If AlDS is not a new disease (and evidence that it is might well be investigated as an act of war by a hostile power with genetic engineering capabilities), then we ought to ask what has changed in order that an endemic disease has now reached epidemic proportions. After all, we should recall that Belgian colonial troops went back and forth from Zaire to Belgium for nearly a hundred years.If there was ever a significant outbreak of AIDS in Belgium, no one has discovered the fact. It seems most likely that the reason is that the large contact rates (k) which characterize the frenetically homosexual communities Which exist in some American cities have never occurred before in the history of the world.

Some Suggestions From The Model

1. The most important elements in AlDS which will cause its essential elimination are:

low yalue of $x$

awfulness of the disease.

2. As the diseased fraction of the target population increases,

k will decrease

Ћ will decreese

„1 will increase 
3. The slogan, frequently used by public officials, to the effect that -AIDS is not just a gay problem" is misleading and harmful. If the public health authorities in the United States had done nothing at all, the total number of deaths from AlDS would be less than will be the case as a result of the policies they have undertaken. The general approach of the civil authorities has been one of "support" of the gay community. The basic issue of homosexual promiscuity as the driving force behind AIDS has been careiully skirted around. Repeatedly, and until relatively recently, gays have been given information which they might interpret as being urged to hang on until hundreds of millions of dollars of government monies produce a vaccine. Suppose, at the beginning of the epidemic, four years ago, the public health authorities had told the gay community, Look, there is an epidemic threatening you; it is transmitted predominantly by anal intercourse. There is little chance that a cure or a vaccine will be available for years. The presence of even a small subgroup within the gay community manifesting highly promiscous homosexual activity is particularly threatening to all of you.- Then, the suppression effects in point 2 above would have proceeded far more quickly than has been the case. A saving of tens of thousands of lives would have been possible. The posture taken by the public health establishment in this country has been disturbingly similar to that of the quack who comforts the cancer patient with nostrums in the present and miracles in the future, rather than encouraging the painful, but more promising techniques of the clinical oncologist. In a paper written in 1983 [1], I predicted that the total fatalities from AIDS in the United States would only be in the 60,000 range. This prediction was based on the assumption that public health 
authorities would make essentially no positive contribution to eradication of the disease. However, I had not counted on their very substantial negative contribution in the form of comforting words which retarded the natural fear induced suppression of the epidemic. My guess now is that the total death count will be much higher than 60,000 , though far fewer than the "millions" predicted by some.

4. Intervention by the state in the form of a publicity campaign giving a graphically realistic assessment of the prognosis of an AIDS victim would have been useful some months ago. However, it appears that the gay communty has by now pretty generally realized that "the cavalry is not going to arrive to save them.Because of the very significant effect by a small subgroup having large numbers of potentially contagious contacts, the closing of meeting places (bath houses, etc.) where high contact rate activity takes place would still be useful. If such places had been closed early on, then the homosexual communities in the United States could possibly have lasted indefinitely. It is not homosexuality which renders AIDS possible. It is the presence of frenetically sexually active individuals in the homosexual community which causes the problem. This fact is not intuitively obvious, but is a clear consequence of the model. It should be pointed out to the gay community that even if most of the members of the community cut down on their activity and/or practice "safe sex," even the less promiscuous are seriously endangered by a small highly promiscous subgroup.

5. Vectoring into the heterosexual population will not be a serious problem because of the much lower level of promiscuity among straights and due to the fact that the mechanism of AIDS transmission is probably much more easily effected from active 
partner to passive partner--more viruses being transmitted in this manner--in the homosexual community an individual will play both roles; and due to the apparently easier transmission in anal versus vaginal intercourse. However, female prostitutes and their clients may be seriously at risk. There may be enough concern on the part of the heterosexual community to engender a neo-Victorianism. Hostility of the heterosexual community to homosexuals will unfortunately be a consequence of the failure of public health officials to tell the straight community that leakage of AIDS into their membership will be minimal.

6. AlDS will eliminate the gay subculture, not through fatality but through fear of fatality. The ultimate "cure- of the disease will be sociological, rather than medical. The presence of visible and organized homosexual societies in the United States will cease.

\section{REFERENCES}

1.Thompson, J.R.(1984) Deterministic versus Stochastic Modeling in Neoplasia,- in Praceedings of the 1984 Summet Camputer Simulatian Canference. pp. 822-825.

2.-Update: Acquired Immunodeficiency Syndrome (AIDS), United States Marbidity and Martality Weekly Repart. Center for Disease Control, צ. 32, 1983, pp. 389-391.

3. -Update: Acquired Immunodeficiency Syndrome (AIDS) :Marbidity and Morlality Weekly Report;"Centers for Disease Control, January 17,1986, v. 35, no. 2, pp. 17-20. 